\section{The high-spin cytochrome o' component of the cytochrome bo-type quinol oxidase in membranes from Escherichia coli: formation of the primary oxygenated species at low temperatures is characterized by a slow 'on' rate and low dissociation constant}

\author{
Robert K. Poole, ${ }^{1}+$ Ian Salmon ${ }^{2}$ and Britton Chance $^{3}$ \\ Author for correspondence: Robert K. Poole. Tel: +1607 255 2423. Fax: + 16072553904.
}

\begin{abstract}
Cytochromes $b$ and $o$ in membrane vesicles from aerobically grown Escherichia coli were readily reduced by succinate; one cytochrome, which we propose should be called cytochrome $\mathrm{O}^{\prime}$, reacted with $\mathrm{CO}$ in the Fe(II) state to give a photodissociable $\mathrm{CO}$ adduct. The photodissociation spectrum (photolysed minus pre-photolysis) at sub-zero temperatures had a relatively high $\gamma / \alpha$ absorbance ratio, indicating a high-spin haem, which, in the reduced state, probably contributes little to the sharp $\alpha$ absorbance of the oxidase complex in membranes. Reaction with oxygen of the unliganded high-spin haem between $-132{ }^{\circ} \mathrm{C}$ and $-95^{\circ} \mathrm{C}$ following photolytic activation gave a product that is identified as the oxygenated form, being spectrally similar to, but not identical with, the $\mathrm{CO}$ adduct. In membranes, the forward velocity constant at $-95^{\circ} \mathrm{C}$ was $61 \mathrm{M}^{-1} \mathrm{~s}^{-1}$, and the dissociation constant was $1.6 \times 10^{-5} \mathrm{M} \mathrm{O}_{2}$, as it is in intact cells. These data clearly distinguish the oxygen-trapping strategy of the cytochrome $o^{\prime}$ in this oxidase from that of cytochrome $a_{3}$ and also suggest that the presence of the soluble flavohaemoglobin (Hmp) in intact cells is without effect on such measurements of the primary oxygen reaction. In view of recent findings that this oxidase complex contains predominantly one mole of haem $O$ and one of haem $B$, a revised nomenclature for the oxidase complex is proposed, namely, cytochrome bo'.
\end{abstract}

Keywords: Escherichia coli, cytochrome bo, cytochrome $o^{\prime}$, electron transfer, quinol oxidase, oxygen reduction

\section{INTRODUCTION}

Escherichia coli contains two terminal oxidases (Poole, 1983, 1988; Poole \& Ingledew, 1987). One of these is generally called cytochrome $o$ (' 0 ' for oxidase), following the classical nomenclature of Castor \& Chance (1959), who first described the photochemical action spectrum of this oxidase. Increasing interest in the cytochrome 0 containing quinol oxidase of E. coli may be attributed to the availability of the purified oxidase and the results of molecular genetic studies of the cyo genes, encoding the subunits of this oxidase, which have revealed significant structural similarities (Chepuri et al., 1990; Saraste et al.,

† Present address (until September 1994): Section of Microbiology, Wing Hall, Cornell University, Ithaca, NY 14853-8101, USA.
1991) between this oxidase and the cytochrome $a a_{3}$-type oxidases of mitochondria and certain bacteria. The oxidase complex comprises four membrane-bound polypeptides (Kita et al., 1984; Matsushita et al., 1984), two moles of haem O (Puustinen \& Wikstrom, 1991), or one of haem O and one of haem B (Puustinen et al., 1992) and a single copper atom, which is coupled to the high-spin haem $\mathrm{O}$ to form a binuclear, ligand-binding site (Salerno et al., 1990).

Little is known of the mechanism of oxygen reduction, which results ultimately in proton-pumping (Puustinen et al., 1991). Early studies (Poole et al., 1979a, b) used the triple-trapping procedure, devised by Chance et al. (1975a), to describe the formation of reaction intermediates and cytochrome oxidation following photolysis of the carbonmonoxy form of the enzyme in intact cells at 
sub-zero temperatures. Although clearly demonstrating the formation of an early intermediate, presumed to be the oxy complex, and the remarkably low dissociation constant $\left(k_{d}\right)$ for the reaction of the enzyme with oxygen, these studies were limited by the relatively poor signal: noise ratios resulting from spectroscopy of frozen cell suspensions, particularly in the $\alpha$ and $\beta$ spectral regions. This work relied on recording the difference spectra of the various states of the oxidase after photolysis, with the spectrum of the pre-photolysis state [i.e. the COliganded, $\mathrm{Fe}(\mathrm{II})$ form] subtracted. Furthermore, recent recognition of the existence of a haemoglobin-like molecule (Hmp) in E. coli (Vasudevan et al., 1991) has raised the question of a permeability or diffusion barrier for oxygen imposed by the cell envelope, which might affect the observed oxygen kinetics in experiments utilizing intact cells.

Here we describe the reactions of cytochrome $o$ in predominantly everted cytoplasmic vesicles at sub-zero temperatures and exploit recent studies of the purified oxidase to interpret more fully the early stages of oxygentrapping and electron transfer. In particular, the recording at $-130^{\circ} \mathrm{C}$ of difference spectra relative to the postphotolysis state facilitates description of the spectrum of the oxy form. Strains that over-express the cyo genes cloned on multi-copy plasmids (such as RG145; Au \& Gennis, 1987), which we have used in recent work (Bolgiano et al., 1991, 1993), synthesize a variant of the oxidase in which the low-spin haem B is replaced to variable extents by a second mole of haem $\mathrm{O}$ (Puustinen et al., 1992). Therefore, a strain that is wild-type with respect to cyo has been used. A revised nomenclature for this oxidase, in line with international recommendations, is proposed.

\section{METHODS}

Cell growth and preparation of membranes $E$. coli strain A1002 (mel ilv lacl metE) was used. The growth mediun contained $\left(1^{-1}\right) \mathrm{K}_{2} \mathrm{HPO}_{4}(4 \mathrm{~g}), \mathrm{KH}_{2} \mathrm{PO}_{4}(1 \mathrm{~g}), \mathrm{NH}_{4} \mathrm{Cl}(1 \mathrm{~g})$, $\mathrm{K}_{2} \mathrm{SO}_{4}(2 \cdot 6 \mathrm{~g}), \mathrm{CaCl}_{2}(0 \cdot 01 \mathrm{~g})$, casamino acids (Difco, $1 \mathrm{~g}$ ), sodium succinate $(10.8 \mathrm{~g})$ and a solution $(10 \mathrm{ml})$ of trace elements (Poole et al., 1979b). After autoclaving, the medium was supplemented with $1 \mathrm{M} \mathrm{MgCl}_{2}\left(1 \mathrm{ml} \mathrm{l}^{-1}\right)$. Cells were growr: in a 61 New Brunswick fermenter, aerated by sparging with sterile air at $61 \mathrm{~min}^{-1}$ and stirred at about 100 r.p.m. The fermenter was inoculated with $1.5 \mathrm{ml}$ of a $21 \mathrm{~h}$ starter culture that had been grown in the same medium in an Erlenmeyer flask containing one-fifth its volume of culture. Cells were harvested in the late exponential phase of growth when oxygen was not limiting for growth; the yield was approx. $3 \mathrm{~g}$ wet wt $\mathrm{l}^{-1}$. Harvested cells were washed in a buffer that contained $50 \mathrm{mM}$ Tris ( $\mathrm{pH} \mathrm{7 \cdot 4),2 \textrm {mM } \mathrm { MgCl }}$ and $1 \mathrm{mM} \mathrm{EGTA}$, then disrupted by sonication. Membranes were prepared by differential centrifugation (Poole \& Haddock, 1974).

Spectroscopy. To a $1 \mathrm{ml}$ portion of membrane particles, in a $2 \mathrm{~mm}$ pathlength cuvette with plexiglass windows, ethylene glycol was added to a final concentration of $30 \%(\mathrm{v} / \mathrm{v})$ (Chance et al., 1975a). The sample was reduced by adding succinate to $12 \mathrm{mM}$ and incubating for $30 \mathrm{~min}$. The cuvette contents were bubbled with $\mathrm{CO}$ for $2.5 \mathrm{~min}$ and then equilibrated at about $-25{ }^{\circ} \mathrm{C}$ for $5 \mathrm{~min}$, after which the cuvette was either plunged into a freezing bath (ethanol/dry ice, $-78^{\circ} \mathrm{C}$ ) or else oxygen was introduced by stirring in small volumes of air-saturated buffer containing $30 \%(\mathrm{v} / \mathrm{v})$ ethylene glycol; the $\mathrm{O}_{2}$ concentration in this buffer was taken to be $1.0 \mathrm{mM}$ at $-23{ }^{\circ} \mathrm{C}$ (Chance et al., 1975a). Dual-wavelength scanning spectrophotometry (Poole et al., 1979b) and multi-wavelength kinetic recordings (Chance et al., 1975b) were made using the apparatus and general methods described elsewhere.

\section{RESULTS}

\section{Spectral changes following low-temperature photolysis}

Physiological substrates readily reduced cytochromes $b$ and $o$ in cytoplasmic membranes. Incubation with succinate for $30 \mathrm{~min}$ typically gave reduction to $86 \%$ (measured at the $\alpha$-peak) of the level obtained with sodium dithionite; absorption maxima (in reduced minus oxidized difference spectra) were centred at $436(\gamma)$ and $563 \mathrm{~nm}(\alpha)$ at room temperature. Succinate reduced cytochrome $o$ to $80-90 \%$ of the level given by dithionite, as assayed by CO difference spectra $(430 \mathrm{~nm}$ trough minus $415 \mathrm{~nm}$ peak) at room temperature (results not shown).

When CO-ligated cytochrome $o$ is exposed to actinic light, the bound $\mathrm{CO}$ is photodissociated, allowing recording of the photodissociation spectrum (photolysed minus prephotolysis), providing the temperature is maintained sufficiently low to prevent recombination of the $\mathrm{CO}$ with the oxidase (Poole et al., 1979a, b). Photolysis to $95 \%$ of the maximum attainable with this flash lamp was attained. The photodissociation difference spectrum, obtained by photolysing an anoxic sample at temperatures between $-100^{\circ} \mathrm{C}$ and $-132{ }^{\circ} \mathrm{C}$, and plotting the post-photolysis minus pre-photolysis difference (not shown), exhibited troughs (in descending order of magnitude) at 412-413, 533-535 (broad) and 566-567 nm. The only prominent peak was at $432 \mathrm{~nm}$, but weak absorbance maxima were observed at 552 and $580 \mathrm{~nm}$. When care was taken to keep the membrane concentration low enough to avoid underestimation of the intense Soret bands in the highly scattering frozen samples, the ratio of absorbance change in the Soret region (432 nm peak minus $413 \mathrm{~nm}$ trough) to that in the $\alpha$-region $(567 \mathrm{~nm}$ trough minus $580 \mathrm{~nm}$, i.e. the ' $\alpha$ peak-trough' as defined by Wood, 1984) was $27-30$. This value and the form of the photodissociation spectra were unaffected by the presence of oxygen in the sample at the time of freeze-trapping. These properties are unlikely to be influenced by interference from the low level of cytochrome $b d$ complex present in the membranes, since (a) the Soret features of the ligand-binding cytochrome $d$ are weak in the $\mathrm{Fe}$ (II) state (Poole, 1983, 1988; Poole et al., 1982), (b) in the absence of oxygen, the CO adduct of cytochrome $d$ reforms immediately after photolysis even at 77K (Poole et al., 1982), and (c) similar results have been observed in membranes from a cytochrome $b d$ deficient, bo-overproducing strain (B. Bolgiano \& R. K. Poole, unpublished data). Puustinen \& Wikstrom (1991) presented a static difference spectrum (CO-reduced minus reduced) of the purified cytochrome bo complex and reported a $\gamma / \alpha$ ratio of $23 \cdot 7$, but the wavelengths used were not cited. 
(a)

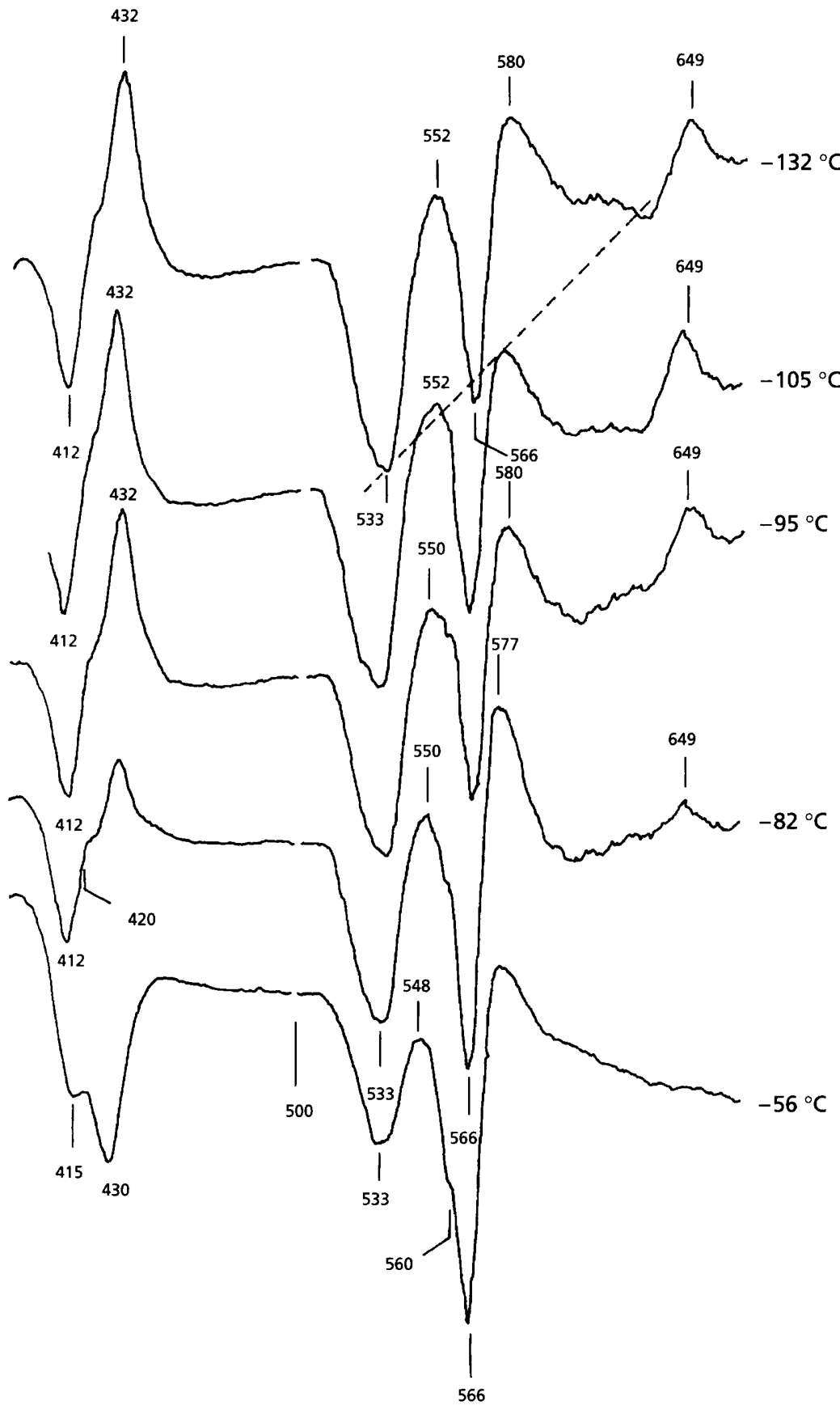

Fig. 1. Difference spectra recorded following photolysis, in the presence of oxygen, of the carbonmonoxy form of cytochrome $o^{\prime}$ in membranes of $E$. coli. The reference spectrum subtracted in each case is that of the pre-photolysis state at the same temperature. Experiments were performed at the temperatures shown. The dashed line drawn between the minima on either side of the $\alpha$-trough for (a), as suggested by Wood (1984), provides a guide to the spin-state of the unligated haem (see Results). The gain on the absorbance scale $>500 \mathrm{~nm}$ is ten times that in the Soret region.
Fig. 1 shows spectra obtained after photolysis of the COligated cytochrome $o$ in the presence of oxygen. It is important to recognize that, in these experiments, the membrane concentration was increased to resolve better the absorbance changes in the $\alpha$ and $\beta$ regions, with consequent diminution of the $\gamma / \alpha$ ratio. Photolysis at $-132^{\circ} \mathrm{C}$, in the presence of oxygen, introduced by stirring to give solution concentrations of $300-400 \mu \mathrm{M}$ (Chance et al., 1975a), resulted in a photodissociation spectrum (Fig. 1a) with troughs (due to loss of the $\mathrm{CO}$ form) at $412(\gamma), 533(\beta)$ and $566(\alpha) \mathrm{nm}$. The minor trough at $633 \mathrm{~nm}$ arises from photolysis of the CO compound of small amounts of cytochrome $d$ with concomitant form- ation of the oxygenated form of cytochrome $d(649 \mathrm{~nm})$. The Soret peak at $432 \mathrm{~nm}$ is attributed to the Fe(II) form of cytochrome $o$. The peak at $552 \mathrm{~nm}$ is attributed mainly to the $\beta$-band of the uncomplexed Fe(II) form but is also influenced by the peak between the $\alpha$ and $\beta$ bands of the CO complex, by comparison with spectra of myoglobin (Wood, 1984). We attribute the peak at $580 \mathrm{~nm}$ to the (weak) $\alpha$-band of the uncomplexed protein. A shoulder at this wavelength is shown in the computed spectrum (total dithionite-reducible haem minus low-spin haem) of the high-spin haem in the purified enzyme (Puustinen et al., 1992) consistent with this assignment. The observation that the $566 \mathrm{~nm}$ trough $(\alpha$-band) does not extend appreci- 


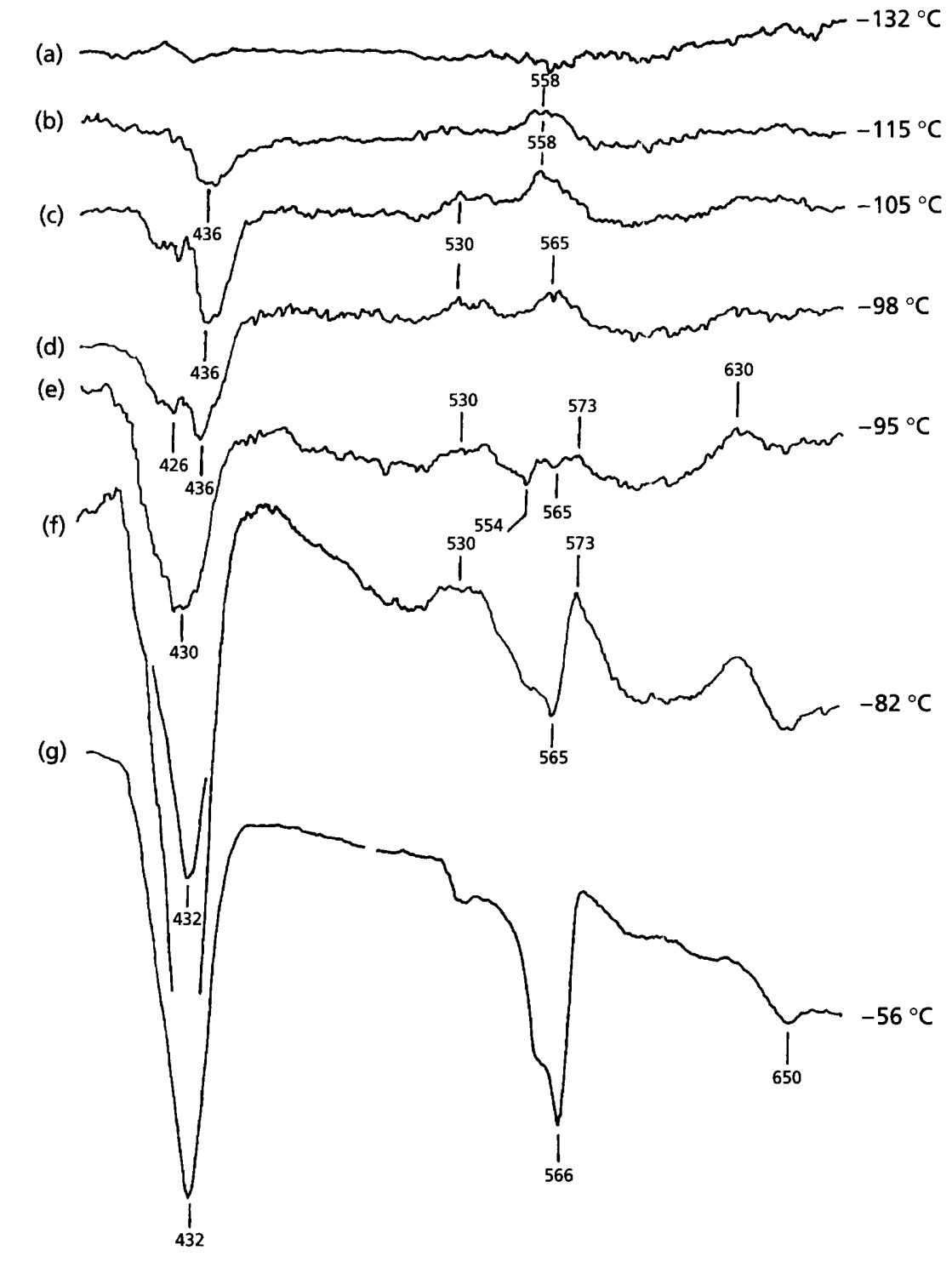

Fig. 2. Difference spectra recorded following photolysis, in the presence of oxygen, of the carbonmonoxy form of cytochrome $o^{\prime}$ in membranes of $E$. coli. The reference spectrum subtracted in each case is that of the post-photolysis state at the same temperature. Experiments were performed at the temperatures shown. ably below the dashed line shown in Fig. 1(a) is indicative of high-spin haem (Wood, 1984). Thus, the photodissociation spectrum in this region, which has contributions from only the ligand-binding cytochrome $\theta$ of the complex, supports the $\mathrm{CO}$ difference spectrum reported by Puustinen \& Wikstrom (1991), who suggested, as did Scott \& Poole (1982), that the CO-reactive high-spin haem contributes little, if at all, to the reduced minus oxidized difference spectrum. Note that the $\alpha$-band of the CO complex (i.e. $566 \mathrm{~nm}$ trough in Fig. 1a) is sharpened (band width at half-peak height, $10 \mathrm{~nm}$ ) relative to the $\beta$-band at $533 \mathrm{~nm}$ (corresponding band width $22 \mathrm{~nm}$ ) or the $\alpha$-band at $580 \mathrm{~nm}$ (band width $17 \mathrm{~nm}$ ), exactly as shown for myoglobin (Wood, 1984).

Figs 1 and 2 show the results of cycling the sample used in Fig. 1(a) to successively higher temperatures after photolysis in the presence of oxygen. In each case, the sample was returned to $-132{ }^{\circ} \mathrm{C}$ to obviate absorbance changes due solely to low temperature intensification (Vincent ot al., 1982). This temperature is close to the lowest attainable with the liquid nitrogen transfer line cryostat. Spectra in Fig. 1 are plotted as differences with the prephotolysis state (i.e. reduced, CO-liganded) subtracted, whereas spectra in Fig. 2 are plotted with the postphotolysis state (i.e. reduced, unliganded) subtracted. After cycling the sample to $-115^{\circ} \mathrm{C}$ (and returning to $-132^{\circ} \mathrm{C}$ ), the spectrum (Fig. $2 \mathrm{~b}$ ) with the post-photolysis form subtracted showed a broad trough centred at $436 \mathrm{~nm}$ and a broad maximum centred at $558 \mathrm{~nm}$. These features developed further after cycling to $-105^{\circ} \mathrm{C}$ (Fig. 2c) and $-98^{\circ} \mathrm{C}$ (Fig. 2d), with the additional appearance of a $\beta$ band centred at $530 \mathrm{~nm}$, and a broad Soret trough extending to about $426 \mathrm{~nm}$. The cytochrome $d$ signals were unchanged. We attribute the absorbance changes between 400 and $600 \mathrm{~nm}$ to the reaction of reduced cytochrome 0 with dioxygen, generating a primary oxygenated form analogous to Compound A of cytochrome $a_{3}$, originally described by Chance $e$ t al. (1975a) at low temperature and described as structurally similar to oxyhaemoglobin and oxymyoglobin. Indeed, the irondioxygen stretching frequency $\left(568 \mathrm{~cm}^{-1}\right)$ is the same as 


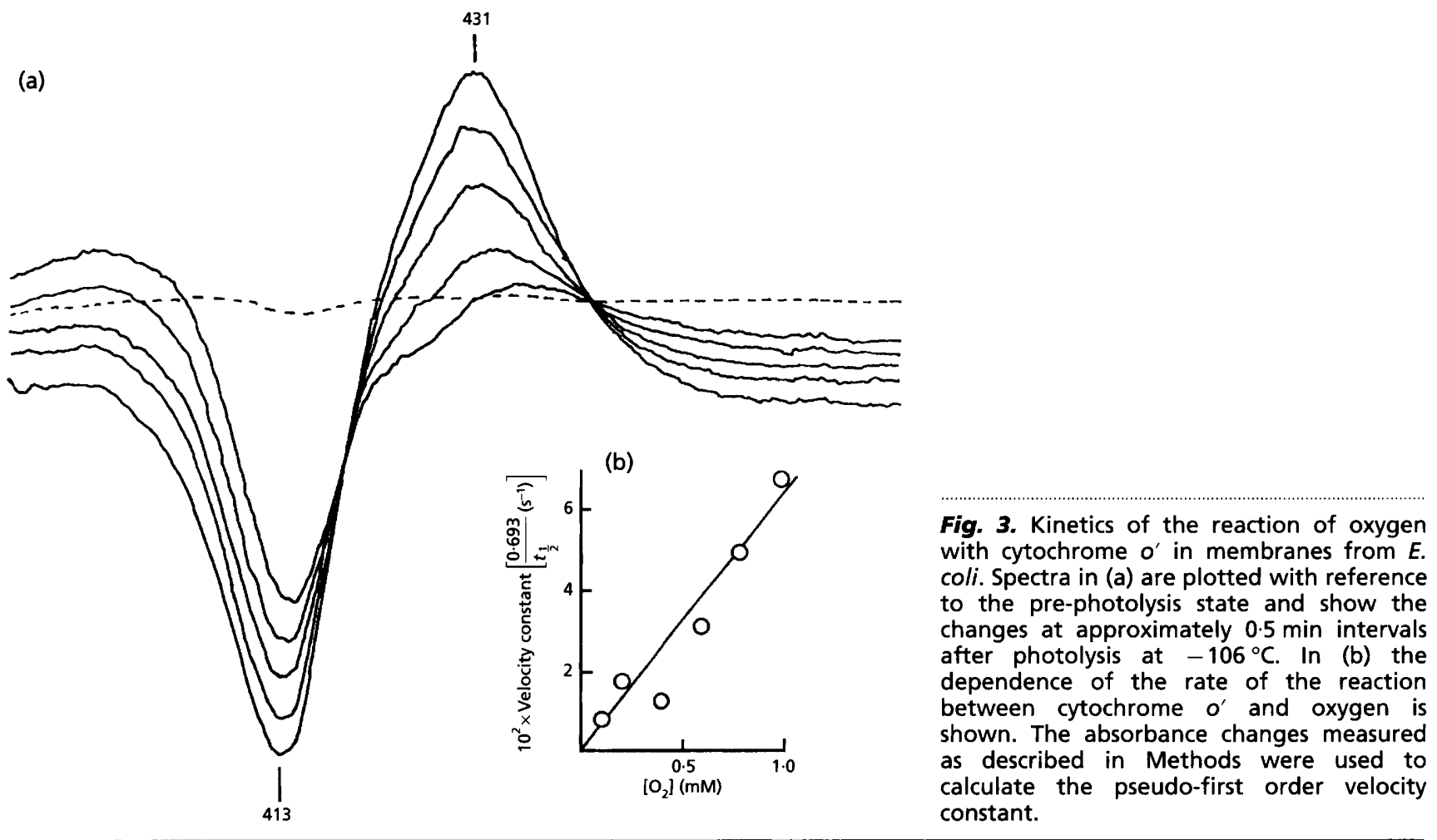

that found in these oxygen-binding proteins (Han et al., 1990). The primary oxygenated intermediate of cytochrome $o$ was first described by Poole et al. (1979a, b) and reported to have spectral properties similar to those of the CO complex. However, the improved spectral resolution obtained here with extensively washed, concentrated membranes from cells grown with vigorous aeration, and after subtracting the post-photolysis and pre-photolysis spectra indicate important differences. Thus, the approach of the Soret features toward the baseline in Fig. 1(a-d) was not symmetrical. Identicality of the oxygenated and $\mathrm{CO}$ adducts would generate a null difference spectrum (oxygenated minus CO-liganded pre-photolysis). Instead, at temperatures between about $-98{ }^{\circ} \mathrm{C}$ and $-132{ }^{\circ} \mathrm{C}$ (Fig. 1a-d), the loss in absorbance at $430 \mathrm{~nm}$ was faster than changes at $415 \mathrm{~nm}$, and the difference spectra in Fig. 2(b-d) showed that the presumptive oxy compound has an absorption coefficient lower than that of the reduced, unliganded form at $430-450 \mathrm{~nm}$, and higher at 530 to about $570 \mathrm{~nm}$.

After cycling the sample to $-95^{\circ} \mathrm{C}$ or $-82{ }^{\circ} \mathrm{C}$ and back to $-132{ }^{\circ} \mathrm{C}$, the difference spectrum (Fig. $2 \mathrm{e}, \mathrm{f}$ ) revealed significant deepening and broadening of the $\gamma$ trough centred at $430 \mathrm{~nm}$ and the development of troughs at 554 and $565 \mathrm{~nm}$, as predicted for oxidation of cytochrome(s) b. In addition, the appearance of a peak at $630 \mathrm{~nm}$ (Fig. 2e) suggested some reduction of cytochrome $d$ and the loss of oxygenated cytochrome $d$, relative to the post-flash (oxygenated) species. At $-56{ }^{\circ} \mathrm{C}$, (Fig. 1e, 2g), the trough due to cytochrome $b$ oxidation was clearly split, suggesting the subsequent oxidation of a cytochrome absorbing maximally at shorter wavelengths.

\section{Kinetics of $\mathrm{CO}$ and $\mathrm{O}_{2}$ binding}

Fig. 3(a) shows the kinetics of the reaction of cytochrome $o$ with oxygen after photolysis at $-106^{\circ} \mathrm{C}$. The baseline was the spectrum of the pre-photolysis (i.e. CO-liganded) state. The asymmetry in the approach of the $413 \mathrm{~nm}$ trough and the $431 \mathrm{~nm}$ peak to the baseline is marked and reflects (see above) the greater similarity of the oxygenated form to the CO adduct at $431 \mathrm{~nm}$ (where the latter has little absorbance) than at $413 \mathrm{~nm}$ (the absorbance maximum of the $\mathrm{CO}$ adduct). There were clear isosbestic points at $418.5 \mathrm{~nm}$ and $441 \mathrm{~nm}$. Similar experiments performed over the temperature range -100 to $-73^{\circ} \mathrm{C}$ gave an Arrhenius plot with an activation energy of about $38 \mathrm{~kJ} \mathrm{~mol}^{-1}$ (results not shown). Similar experiments in the absence of oxygen (not shown) gave symmetrical absorbance changes in the Soret region with respect to the baseline, and an activation energy in the temperature range $-80^{\circ} \mathrm{C}$ to $42{ }^{\circ} \mathrm{C}$ of $35 \mathrm{~kJ} \mathrm{~mol}^{-1}$ (not shown).

We previously reported a surprisingly low dissociation constant and first-order rate constant for the reaction between cytochrome $o$ and oxygen (Poole $e t$ al., 1979a). To investigate the possibility that, in intact cells, the cell envelope presented a significant permeability barrier to oxygen diffusion to the oxidase, the experiments were repeated with cytoplasmic membrane particles, which are likely to exist largely as everted membrane vesicles after cell disruption by sonication (Poole, 1993). Recordings were made with the double dual-wavelength apparatus described by Chance et al. (1975b) at 430 minus $450 \mathrm{~nm}$. The results in Fig. 3(b) show some scatter, reflecting the difficulty in controlling oxygen additions to the viscous ethylene glycol-containing sample in the dark, but are 
representative of three such experiments. A line of best fit gives a $K_{+1}$ of $61 \mathrm{M}^{-1} \mathrm{~s}^{-1}$, significantly higher than that obtained with whole cells $\left(0.9 \mathrm{M}^{-1} \mathrm{~s}^{-1}\right.$ at $-101{ }^{\circ} \mathrm{C}$; Poole et al., 1979a), but an order of magnitude slower than the $K_{+1}$ value for membrane-bound cytochrome $a a_{3}$ $\left(685 \mathrm{M}^{-1} \mathrm{~s}^{-1}\right.$; Chance et al., 1975a). Nevertheless, the dissociation constant is clearly very low. An estimate of $K_{-1}$ (the velocity when the oxygen concentration is zero, the intercept) of $0.1 \times 10^{-2} \mathrm{~s}^{-1}$ gives a $k_{\mathrm{d}}$ of $1.6 \times 10^{-5} \mathrm{M} \mathrm{O}_{2}$, very close to the value obtained in whole cells (Poole et al., 1979b). Despite some uncertainty in the precise values, the $k_{\mathrm{d}}$ is clearly lower than the value of $0.5 \times 10^{-3} \mathrm{M}$ reported for cytochrome $a a_{3}$ (Chance et al., 1975a).

\section{DISCUSSION}

The results presented here demonstrate the predominantly high-spin character of the photodissociation spectrum of the ligand-binding haem in the E. coli cytochrome ocontaining terminal oxidase complex in membranes. This high-spin assignment is consistent with the ESR studies of Hata et al. (1985), who used a purified oxidase preparation, and those of Salerno et al. (1990), who described a biphasic potentiometric titration of the $g=6$ (i.e. high-spin) signal with components having $E_{\mathrm{m}, 7}$ values of +180 and $+280 \mathrm{mV}$. The high potential side of the bell-shaped titration curve (where signal height at $g=$ 6 diminished at higher potentials) was attributed to oxidation of the copper centre which, when in the $\mathrm{Cu}(\mathrm{II})$ form is spin-coupled to a haem, presumably the ligandbinding haem at the active site of the enzyme.

The $\gamma / \alpha$ ratio in the photodissociation spectrum at low sample concentrations is $27-30$, a value that is significantly higher than that anticipated for a low-spin haem, yet slightly less than typical high-spin haem $B$ as in myoglobin $(\gamma / \alpha=32$; Wood, 1984). Although the presence of a mixed spin state cannot be ruled out, the weak $\alpha$-trough of the CO difference spectrum (Puustinen \& Wikstrom, 1991), together with the photodissociation spectra (Fig. 1 ), and the low temperature narrowing of the $\alpha$-band of the CO complex, are all suggestive of high-spin haem.

Reports of the atypical pyridine haemochrome spectrum of haems in membranes from cytochrome o-overproducing E. coli strains (Bolgiano et al., 1991) and the subsequent demonstration of novel haem (O) in the oxidase purified from such a strain (Puustinen \& Wikstrom, 1991) should prompt careful reconsideration of the nomenclature of this oxidase. 'On the basis of the strong homology between cytochrome $o$ and cytochrome $a a_{3}$-type oxidases', Puustinen and Wikstrom (1991) proposed the term 'cytochrome ${ }^{00_{3}}$ ', which, they suggest, 'also appears historically pertinent'. We propose instead that the 1989 Recommendations of the Nomenclature Commission of the International Union of Biochemistry (Palmer \& Reedijk, 1992) be adopted and that subsequent findings that the enzyme in wild-type cells contains one high-spin haem $\mathrm{O}$ at the binuclear site and one low-spin haem B (Puustinen et al., 1992) be reflected in the name. The haem $(\mathrm{O})$ analogous to that in cytochrome $a_{3}$ is in a non-haemochrome linkage, being high-spin and ligandbinding, and should be called cytochrome $o^{\prime}$. The resulting nomenclature, $b o^{\prime}$, is in accord with the recommended name for cytochrome $c$ oxidase $a a_{3}$ (EC 1.9.3.1), i.e. cytochrome $a a^{\prime}$, although this name has not been generally adopted. In our view, cytochrome $b o^{\prime}$ is more appropriate than $o_{3}$ or $b o_{3}$, neither of which is 'historically pertinent'. The consecutive subscript numbering was intended to distinguish a cytochrome from previously named variants of the same type. Thus, Keilin (1966) named cytochromes $a, a_{1}, a_{2}$ (now $d$, a chlorin) and $a_{3}$, but Castor \& Chance (1959) defined previously only one cytochrome $o$ in this organism and no other types of haem $O$ have been described subsequently; subscripts at this stage appear unnecessary and confusing.

The ability to record photodissociation spectra at the temperatures reported in this paper $\left(-132{ }^{\circ} \mathrm{C}\right.$ or higher $)$ has been reported only for cytochromes $a_{3}$ and $o^{\prime}$. As in the case of cytochrome $a_{3}$, this is attributed to the presence in the cytochrome $b o^{\prime}$ complex of a copper atom, which, in its $\mathrm{Cu}(\mathrm{I})$ state, binds photodissociated $\mathrm{CO}$, effectively slowing geminate recombination of the ligand to the high-spin haem. This is supported by infrared spectroscopy (Chepuri et al., 1990) and by the finding that in E. coli grown under conditions of copper deficiency in a chemostat (Ciccognani et al., 1992) photodissociation spectroscopy grossly underestimates the quantification of cytochrome $o^{\prime}$, by lowering cellular and oxidase copper levels and permitting $\mathrm{CO}$ recombination as in myoglobin (Wood, 1984) or cytochrome $d$ (Poole et al., 1982).

At $-132{ }^{\circ} \mathrm{C}$, the photodissociation spectrum of cytochrome $o^{\prime}$ is unaffected by the presence (Fig. 1) or absence (not shown) of oxygen. This is attributed to the negligible reaction of oxygen with the $\mathrm{Fe}(\mathrm{II})$ haem at this temperature. The photodissociation spectrum observed in membranes is very similar to, but inverted with respect to, the CO difference spectra for intact cells (Bolgiano et al., 1991) and for the purified oxidase (Puustinen et al., 1991) (Table 1). Photochemical action spectra have been described for E. coli only twice; in such spectra, peaks are observed at wavelengths corresponding to the absorption maxima of the CO-inhibited form of the functional oxidase. The original action spectrum of Castor \& Chance (1959) is almost identical, after inversion, to the photodissociation spectrum described here, but for the absence of the broad $580 \mathrm{~nm}$ signal. The action spectrum of Edwards et al. (1981) is also similar, but for their inability to record signals below about $540 \mathrm{~nm}$, due to inadequate laser light intensity at these wavelengths. The data in Table 1 show that the oxidase whose properties are described here is spectrally similar to the ligand-binding haem $o^{\prime}$ of the purified oxidase (Puustinen \& Wikstrom, 1991) and to the functional oxygen-reactive cytochrome observed in photochemical action spectra.

In this work, the spectral changes that follow reaction of the oxidase with oxygen at sub-zero temperatures have been followed by recording spectra with respect to both the pre-photolysis state (i.e. reduced $+\mathrm{CO}$ ), as in previous work, and the post-photolysis state at $-132^{\circ} \mathrm{C}$ (i.e. reduced, unliganded). The latter type of difference 
Table 1. Comparison of absorption maxima in CO difference spectra for some haem O- and B-containing proteins

\begin{tabular}{|c|c|c|c|c|c|}
\hline & \multicolumn{2}{|c|}{$\beta$-bands (nm) } & \multicolumn{2}{|c|}{$\alpha$-bands (nm) } & \multirow[t]{2}{*}{ Reference } \\
\hline & $\begin{array}{c}\mathrm{Fe}(\mathrm{II}) \mathrm{CO} \\
\left(\lambda_{\max }\right)\end{array}$ & $\begin{array}{l}\mathrm{Fe}(\mathrm{II}) \\
\left(\lambda_{\min }\right)\end{array}$ & $\begin{array}{c}\mathrm{Fe}(\mathrm{II}) \mathrm{CO} \\
\left(\lambda_{\max }\right)\end{array}$ & $\begin{array}{c}\mathrm{Fe}(\mathrm{II}) \\
\left(\lambda_{\min }\right)\end{array}$ & \\
\hline E. coli cytochrome $o^{\prime *}$ & 537 & 552 & 570 & 585 & Puustinen \& Wikstrom (1991)† \\
\hline E. coli cells & 535 & 550 & 567 & - & Castor \& Chance (1959) $\ddagger$ \\
\hline E. coli cells & - & 555 & 570 & 584 & Edwards et al. (1981) $\ddagger$ \\
\hline E. coli membranes (RG145)* & 530 & 550 & 565 & 583 & Bolgiano et al. (1991)† \\
\hline E. coli membranes & 535 & 552 & 567 & 580 & This paper $₫$ \\
\hline Myoglobin & 538 & 558 & 579 & 594 & Wood (1984) \\
\hline
\end{tabular}

* Over-producing strain; such strains synthesize variant forms of the oxidase with higher ratios of haem O:haem B than in the wild-type. †CO-difference spectrum, room temperature.

$\ddagger$ Photochemical action spectrum, room temperature.

$\S$ Photodissociation spectrum, $-130^{\circ} \mathrm{C}$. Spectrum inverted with respect to CO-difference spectrum.

spectrum shows more clearly the spectral features of the initial ligand-binding reaction than hitherto. They show that the first optically detectable intermediate has absorbance bands that are more intense than those of the reduced form (the 'baseline spectrum') in the 530-570 $\mathrm{nm}$ region and less intense in the Soret region near $436 \mathrm{~nm}$. These changes can be assigned to the formation of an oxygenated intermediate $\left(\mathrm{Fe}^{2+} \mathrm{O}_{2}\right.$ or $\left.\mathrm{Fe}^{3+} \mathrm{O}_{2}^{-}\right)$described previously in kinetic studies (Poole et al., 1979a, b).

At the lowest temperatures studied, the spectrum (Fig. 2a) exhibits a $558 \mathrm{~nm}$ peak and a $436 \mathrm{~nm}$ trough. After photolysis at $-105^{\circ} \mathrm{C}$ to $98{ }^{\circ} \mathrm{C}$, however, the $\alpha / \beta$ region has peaks at $530-565 \mathrm{~nm}$ and a trough is developing at 426-430 nm. At this point, the difference spectrum (postphotolysis minus reduced, unliganded) is similar to a photodissociation spectrum obtained in the absence of oxygen (see, for example Bolgiano et al., 1993). This suggests that at about $-98^{\circ} \mathrm{C}$ the species formed is an oxygenated form with a spectrum similar to that of the $\mathrm{CO}$ species. The spectral similarity of the oxygen and $\mathrm{CO}$ adducts of haem proteins is well established (Wood, 1984). The form of the enzyme observed after photolysis at lower temperatures (e.g. Fig. 2a) is unclear and must be the subject of future studies.

Puustinen \& Wikstrom (1991) have drawn attention to the distinctive blue-shifted pyridine haemochrome spectrum of o-type cytochromes, compared to haem B proteins, as did Bolgiano et al. (1991). The comparative data in Table 1 also reveal significant differences between the CO difference spectra of the two haem types, taking myoglobin as a well characterized example of a high-spin protohaem protein. The $\beta$-bands of $\mathrm{Fe}(\mathrm{II})$ myoglobin are shifted about $5 \mathrm{~nm}$ to higher wavelengths (compared with the average values for cytochrome $o^{\prime}$ (Table 1), whilst the $\alpha$-bands are shifted about $11 \mathrm{~nm}$ further to the red than the corresponding cytochrome $o^{\prime}$ bands. Both haems have broad, weak absorbances in the unliganded, reduced state and thus contribute little to reduced minus oxidized spectra in the $\alpha$ - and $\beta$-regions, as first suggested by Scott
\& Poole (1982). This finding requires careful consideration in spectral studies of cytochrome o-containing oxidases.

Although the physiological function of the haemoglobinlike protein in E. coli (Vasudevan et al., 1991) is not yet known, it does bind oxygen (Ioannidis et al., 1992; Orii et al., 1992) and its properties suggest that it could have oxygen transport properties similar to those postulated for the Vitreoscilla haemoglobin (Khosla \& Bailey, 1988). Nevertheless, its presence (at wild-type levels) in the intact cells used previously (Poole et al., 1979a, b) does not explain the remarkably low dissociation constant described in that paper, since extensively washed membranes (this paper) reveal similar kinetic parameters.

\section{ACKNOWLEDGEMENTS}

This work was supported by grants to R.K.P. from the Royal Society and the SERC.

\section{REFERENCES}

Au, D. C.-T. \& Gennis, R. B. (1987). Cloning of the cyo locus encoding the cytochrome $o$ terminal oxidase complex of Escherichia coli. J Bacteriol 169, 3237-3242.

Bolgiano, B., Salmon, I., Ingledew, W. J. \& Poole, R. K. (1991). Redox analysis of the cytochrome $o$-type quinol oxidase complex of Escherichia coli reveals three redox components. Biochem $J$ 274, 723-730.

Bolgiano, B., Salmon, I. \& Poole, R. K. (1993). Reactions of the membrane-bound cytochrome bo terminal oxidase of Escherichia coli with carbon monoxide and oxygen. Biochim Biophys Acta 1141, 95-104.

Castor, L. N. \& Chance, B. (1959). Photochemical determinations of the oxidases of bacteria. J Biol Chem 234, 1587-1592.

Chance, B., Graham, N. \& Legallais, V. (1975a). Low temperature trapping method for cytochrome oxidase intermediates. Anal Biochem 67, 552-579.

Chance, B., Legallais, V., Sorge, J. \& Graham, N. (1975b). A versatile time-sharing multichannel spectrophotometer, reflectometer and fluorometer. Anal Biochem 67, 498-514. 
Chepuri, V., Lemieux, L., Au, D. C.-T. \& Gennis, R. B. (1990). The sequence of the cyo operon indicates substantial similarities between the cytochrome $o$ ubiquinol oxidase of Escherichia coli and the $a a_{3}$. type family of cytochrome $c$ oxidases. J Biol Chem 265, 11185-11192.

Ciccognani, D. T., Hughes, M. N. \& Poole, R. K. (1992). Carbon monoxide-binding properties of the cytochrome bo quinol oxidase complex in Eschericbia coli are changed by copper deficiency in continuous culture. FEMS Microbiol Lett 94, 1-6.

Edwards, C., Beer, S., Siviram, A. \& Chance, B. (1981). Photochemical action spectra of bacterial a- and o-type oxidases using a dye laser. FEBS Lett 128, 205-207.

Han, S., Ching, Y.-C. \& Rousseau, D. L. (1990). Primary intermediate in the reaction of oxygen with fully reduced cytochrome $c$ oxidase. Proc Natl Acad Sci US A 87, 2491-2495.

Hata, A., Kirino, Y., Matsuura, K., Itoh, S., Hiyama, T., Konishi, K., Kita, K. \& Anraku, Y. (1985). Assignment of ESR signals of Escbericbia coli terminal oxidases. Biochim Biophys Acta 810, 62-72.

Ioannidis, N., Cooper, C. E. \& Poole, R. K. (1992). Spectroscopic studies on an oxygen-binding haemoglobin-like flavohaemoprotein from Escherichia coli. Biochem J 288, 649-655.

Keilin, D. (1966). The History of Cell Respiration and Cytocbrome. Cambridge: Cambridge University Press.

Khosla, C. \& Bailey, J. E. (1988). Heterologous expression of a bacterial haemoglobin improves the growth properties of recombinant Escherichia coli. Nature 331, 633-635.

Kita, K., Konishi, K. \& Anraku, Y. (1984). Terminal oxidases of Escherichia coli respiratory chain. I. Purification and properties of cytochrome $b_{562}-o$ complex from cells in the early exponential phase of aerobic growth. $J$ Biol Chem 259, 3368-3374.

Matsushita, K., Patel, L. \& Kaback, H. R. (1984). Cytochrome $o$ type oxidase from Eschericbia coli. Characterization of the enzyme and mechanism of electrochemical proton gradient generation. Biochemistry 23, 4703-4714.

Orii, Y., loannidis, N. \& Poole, R. K. (1992). The oxygenated flavohaemoglobin from Escherichia coli: evidence from photodissociation and rapid-scan studies for two kinetic and spectral forms. Biochem Biophys Res Commun 187, 94-100.

Palmer, G. \& Reedijk, J. (1992). Nomenclature Committee of the International Union of Biochemistry (NC-IUB). Nomenclature of electron-transfer proteins. Recommendations 1989. J Biol Chem 267, 665-677.

Poole, R. K. (1983). Bacterial cytochrome oxidases. A functionally and structurally diverse group of electron-transfer proteins. Biocbim Biopbys Acta 726, 205-243.

Poole, R. K. (1988). Bacterial cytochrome oxidases. In: Bacterial Energy Transduction, pp. 231-291. Edited by C. Anthony. London: Academic Press.

Poole, R. K. (1993). The isolation of membranes from bacteria. In Methods in Molecular Biology, Vol. XX, Biomembrane Protocols: Isolation and Analysis. Edited by J. M. Graham. Totowa, NJ: Humana Press (in press).

Poole, R. K. \& Haddock, B. A. (1974). Energy-linked reduction of nicotinamide-adenine dinucleotide in membranes derived from normal and various respiratory-deficient mutant strains of Escherichia coli. Biochem J 144, 77-85.

Poole, R. K. \& Ingledew, W. J. (1987). Pathways of electrons to oxygen. In Escherichia coli and Salmonella typhimurium: Cellular and Molecular Biology, vol. 1, pp. 170-200. Edited by F. C. Neidhardt, J. L. Ingraham, K. B. Low, B. Magasanik, M. Schaechter \& H. E. Umbarger. Washington, DC: American Society for Microbiology.

Poole, R. K., Waring, A. J. \& Chance, B. (1979a). Evidence for a functional oxygen-bound intermediate in the reaction of Eschericbia coli cytochrome $o$ with oxygen. FEBS Lett 101, 56-58.

Poole, R. K., Waring, A. J. \& Chance, B. (1979b). The reaction of cytochrome 0 in Escherichia coli with oxygen. Low-temperature kinetic and spectral studies. Biochem J 184, 379-389.

Poole, R. K., Sivaram, A., Salmon, I. \& Chance, B. (1982). Photolysis at very low temperatures of CO-liganded cytochrome oxidase (cytochrome $d$ ) in oxygen-limited Escherichia coli. FEBS Lett 141, 237-241.

Puustinen, A. \& Wikstrom, M. (1991). The heme groups of cytochrome o from Escherichia coli. Proc Natl Acad Sci USA 88, 6122-6126.

Puustinen, A., Finel, M., Haltia, T., Gennis, R. B. \& Wikstrom, M. (1991). Properties of the two terminal oxidases of Escherichia coli. Biochemistry 30, 3936-3942.

Puustinen, A., Morgan, J. E., Verkhovsky, M., Thomas, J. W., Gennis, R. B. \& Wikstrom, M. (1992). The low-spin heme site of cytochrome $o$ from Escherichia coli is promiscuous with respect to heme type. Biochemistry 31, 10363-10369.

Salerno, J. C., Bolgiano, B., Poole, R. K., Gennis, R. B. \& Ingledew, W. J. (1990). Heme-copper and heme-heme interactions in the cytochrome bo-containing quinol oxidase of Escherichia coli. J Biol Chem 265, 4364-4368.

Saraste, M., Holm, L., Lemieux, L., Luben, M. \& Van der Oost, J. (1991). The happy family of cytochrome oxidases. Biochem Soc Trans 19, 608-612.

Scott, R. I. \& Poole, R. K. (1982). A re-examination of the cytochromes of Escherichia coli using fourth-order finite difference analysis: their characterization under different growth conditions and accumulation during the cell cycle. J Gen Microbiol 128, 1685-1696.

Vasudevan, S. G., Armarego, W. L. F., Shaw, D. C., Lilley, P. E., Dixon, N. E. \& Poole, R. K. (1991). Isolation and nucleotide sequence of the $h m p$ gene that encodes a haemoglobin-like protein in Escherichia coli. Mol \& Gen Genet 226, 49-58.

Vincent, J.-C., Kumar, C. \& Chance, B. (1982). Quantitative visible spectroscopy at low temperatures: a systematic examination. Anal Biochem 126, 86-93.

Wood, P. M. (1984). Bacterial proteins with CO-binding b- or ctype haem. Functions and absorption spectroscopy. Biochim Biophys Acta 768, 293-317.

Received 8 September 1993; revised 16 November 1993; accepted 1 December 1993. 